\title{
Contribution to Analysis of Co/Cu Substituted Ni-Zn Ferrites
}

\author{
G. S. V. R. K. Choudary, ${ }^{1}$ P. Prameela, ${ }^{2}$ M. Chaitanya Varma, ${ }^{3}$ \\ A. Mahesh Kumar, ${ }^{4}$ and K. H. Rao ${ }^{5}$ \\ ${ }^{1}$ Department of Physics, Bhavan's Vivekananda College, Sainikpuri, Secunderabad, Andra Pradesh 500094, India \\ ${ }^{2}$ Department of Physics, Andhra University, Visakhapatnam, Andra Pradesh 530045, India \\ ${ }^{3}$ Department of Natural Sciences, College of Natural and Computational Sciences, Wollega University, P.O. Box 395, \\ Nekemte, Ethiopia \\ ${ }^{4}$ Department of Physics, GITAM University, Visakhapatnam, Andra Pradesh 530045, India \\ ${ }^{5}$ Department of Physics, RGU-IIIT Nuzvid, Nuzvid, Andhra Pradesh 521201, India
}

Correspondence should be addressed to G. S. V. R. K. Choudary; gsvrk.choudary@gmail.com

Received 13 July 2013; Accepted 12 September 2013

Academic Editors: A. Chatterji and A. Cremades

Copyright (c) 2013 G. S. V. R. K. Choudary et al. This is an open access article distributed under the Creative Commons Attribution License, which permits unrestricted use, distribution, and reproduction in any medium, provided the original work is properly cited.

In this communication, $\mathrm{Co} / \mathrm{Cu}$ substituted $\mathrm{Ni}-\mathrm{Zn}$ ferrites processed through sol-gel synthesis using polyethylene glycol (PEG) as a chelating agent are studied, intending to aid in understanding and choosing the optimum ferrite material for high frequency applications. Lattice constant and average crystallite size have been estimated from FWHM of the X-ray diffraction peaks, and these parameters are understood by considering the ionic radii of the substituted as well as the replacing ions. Observed variations in saturation magnetization and initial permeability for these ferrites have been explained on the basis of anisotropy contribution for cobalt and segregation of copper at grain boundaries evident from scanning electron micrographs.

\section{Introduction}

The increasing demand for ferrite materials for core applications having reduced size, weight, and cost necessitates to develop ferrites containing ultrafine particles with improved efficiency at high frequencies. Ferrites show interesting magnetic and electronic properties as the particle size decreases compared with those of the bulk ferrites. The extensive study on mixed ferrite systems reveals that $\mathrm{Ni}-\mathrm{Zn}$ ferrites are wellknown core materials suitable for high frequency applications up to $100 \mathrm{MHz}$ due to their high value of saturation magnetization, moderate permeability, and high resistivity parameters responsible for low losses [1-4]. Though ultrafine particles provide large grain boundary area to develop resistivity by many folds, expected enhancement in magnetization is hindered by these tiny grains to extend the cooperative effects among the particles. This may be achieved by substitution of a diamagnetic impurity ion in Ni-Zn ferrites which tend to occupy tetrahedral sites or a ferromagnetic impurity having strong preference for octahedral sites of the spinel lattice supposed to be substituted. In case of nanoferrites, inversion of the ion occurs against its natural preference (in bulk ferrites) as reported earlier [3].

By considering this argument, in this communication, $\mathrm{Cu} / \mathrm{Co}$ ions have been substituted, replacing nickel ions in sol-gel synthesized $\mathrm{Ni}-\mathrm{Zn}$ ferrites using polyethylene glycol. PEG serves as a chelating agent in controlling the crystallite size by arresting the particles in the polymer matrix and facilitates homogeneous dispersion of ferrite nanoparticles.

\section{Experimental Details}

The method of preparation of samples was described elsewhere [4]. X-ray diffraction (XRD) is used for the identification of the material phases and crystal structure, determination of average crystallite size and lattice constant. Powder $\mathrm{X}$-ray diffraction measurements for all the samples have been taken on Inel Equinox 3000 using Co- $\mathrm{K}_{\alpha}$ radiation (1.7889 $\AA$ ) and Bruker AXS D8 diffractometer with $\mathrm{Cu}-\mathrm{K}_{\alpha}$ radiation (1.5418 $\AA$ ). Room temperature magnetization of the sample 
was measured using a vibration sample magnetometer (115 PAR-EG\&G Model) under an external magnetic field of $20 \mathrm{kOe}$. Impedance analyzer was used to measure the permeability of toroid shaped samples.

\section{Results and Discussion}

Figures 1, 2, and 3 show X-ray diffractograms for the ferrite samples of the general formulas $\mathrm{Ni}_{0.65} \mathrm{Zn}_{0.35} \mathrm{Fe}_{2} \mathrm{O}_{4}$, $\mathrm{Ni}_{0.65-x} \mathrm{Zn}_{0.35} \mathrm{Co}_{x} \mathrm{Fe}_{2} \mathrm{O}_{4}(x=0.04,0.08,0.12,0.16,0.20,0.24$, $0.28)$, and $\mathrm{Ni}_{0.65-x} \mathrm{Zn}_{0.35} \mathrm{Cu}_{x} \mathrm{Fe}_{2} \mathrm{O}_{4}(x=0.06,0.12,0.18,0.24$, $0.30)$. The measured $d$-values are found to be in good agreement with those reported in the literature [5] confirming single phase spinel structure for all the samples. Accurate estimation of lattice constant is done from the extrapolation of calculated lattice parameter against Nelson-Riley function [6], provided that the lattice constant for the basic Ni-Zn ferrite is $8.3708 \AA$, in agreement with what is reported in [1].

A gradual increase in lattice constant has been observed from $8.3708 \AA$ to $8.384 \AA$ with increasing cobalt content (Figure 4), whereas lattice constant increases from $8.3708 \AA$ to $8.3814 \AA$ for copper substitution barring $x=0.24$ and 0.30 . It is well known $[7,8]$ that if the radius of the substituent ion is larger than the displaced ion, the lattice expands, and hence, the lattice constant increases or vice versa. In general, an increase in the lattice constant is expected for both cobalt and copper substitutions as the radii of $\mathrm{Co}^{2+}(0.745 \AA)$ and $\mathrm{Cu}^{2+}$ ions $(0.70 \AA)[9,10]$ are quite larger than that of the displaced $\mathrm{Ni}^{2+}$ ion $(0.69 \AA)$. The observed increase in lattice constants for both cobalt and copper ions infers entry of both these ions into the spinel lattice. The slight decrease of lattice constant for the two extreme compositions of copper substituted $\mathrm{Ni}-\mathrm{Zn}$ ferrites is attributed to lattice shrinkage caused by segregation of copper ions at the grain boundaries as evident from SEM measurements (Figure 6(e)).

Typical scanning electron micrographs for Ni-Co-Zn and $\mathrm{Ni}-\mathrm{Cu}-\mathrm{Zn}$ are shown in Figures 5(a)-5(h) and 6(a)-6(e). Grain size could not be estimated from the SEM images as fine particles were noticed within the resolution provided by the micrographs. A clear indication of agglomerated structures and increase in particle size is evident with the increasing concentration of cobalt, while an increase in particle size and densification were observed with increasing copper content (Figures 7 and 8).

Room temperature magnetic hysteresis loops for $\mathrm{Ni}_{0.65-x} \mathrm{M}_{x} \mathrm{Zn}_{0.35} \mathrm{Fe}_{2} \mathrm{O}_{4},(\mathrm{M}=\mathrm{Co}, \mathrm{Cu})$ have been recorded, indicating that these ferrites possess soft ferrimagnetic behavior. A gradual increase in saturation magnetization and coercivity is noticed in case of cobalt substitution. The observed variations in saturation magnetization $\left(M_{s}\right)$, coercivity $\left(H_{c}\right)$, and magnetic anisotropy $(K)$ as a function of cobalt concentration are depicted in Figures 9 and 10.

The observed variations in saturation magnetization can be understood on the basis of superexchange interactions among both the tetrahedral (A) and octahedral [B] site ions in the spinel lattice. In ferrites, according to Neel [11], there exist three kinds of interactions: the interaction between the various magnetic ions located at A-site (AA interaction),

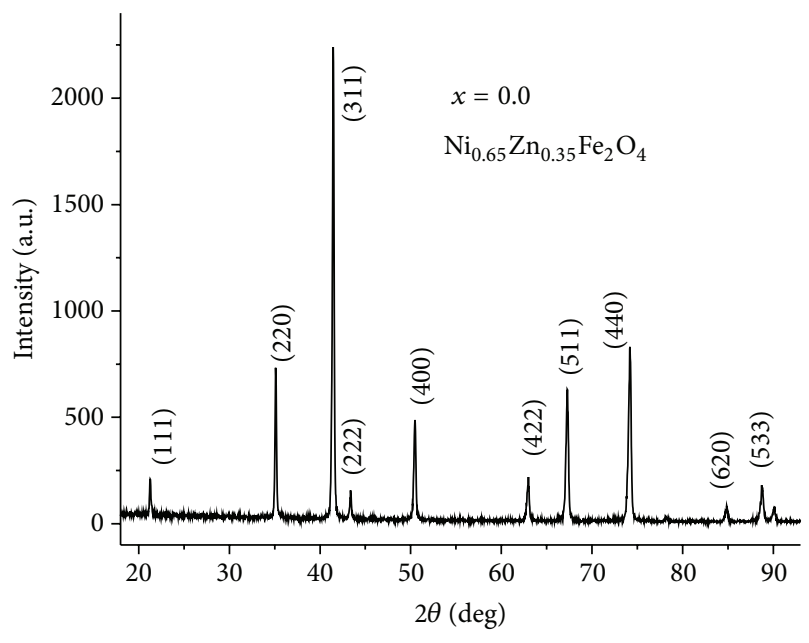

Figure 1: X-ray diffraction patterns of Ni-Zn ferrite.

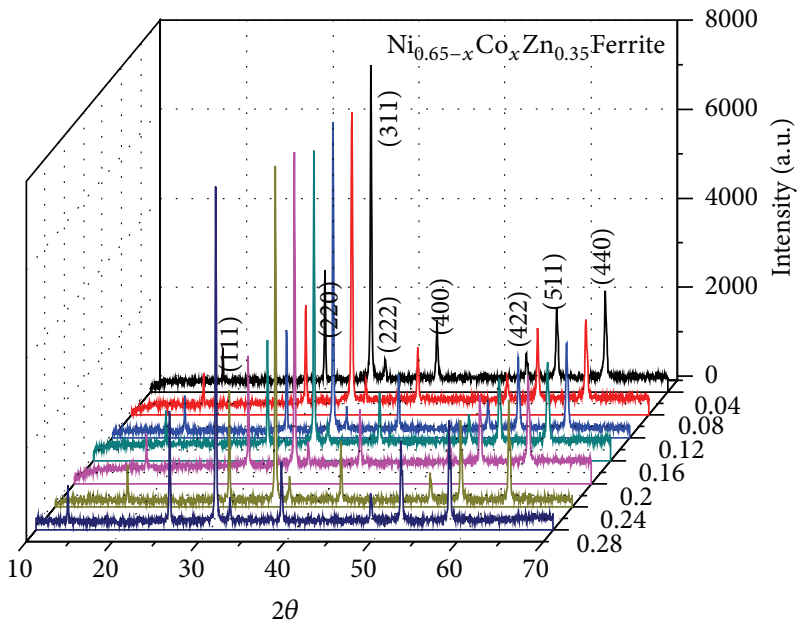

FIGURE 2: X-ray diffraction patterns of cobalt substituted Ni-Zn ferrite samples.

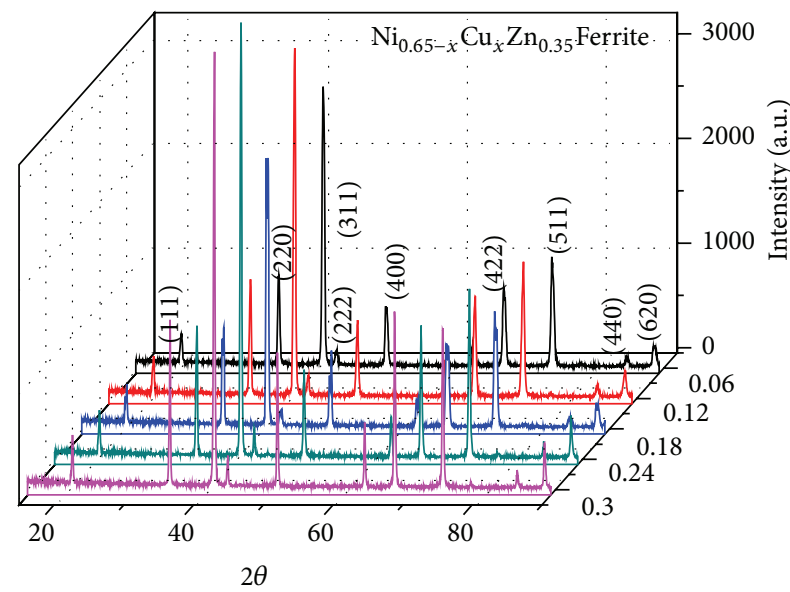

FIGURE 3: X-ray diffraction patterns of copper substituted Ni-Zn ferrite samples. 


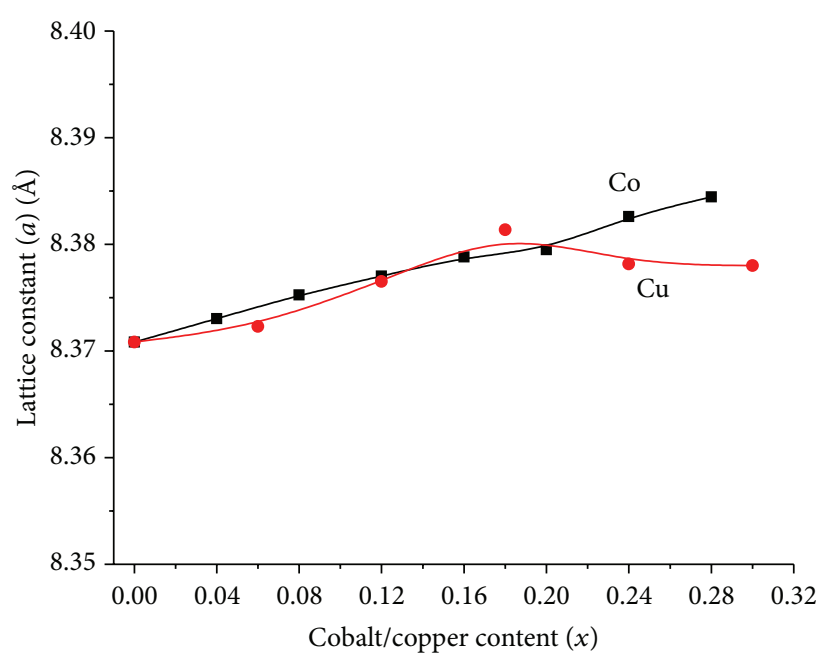

FIGURE 4: Variation in lattice constant with cobalt and copper concentrations.

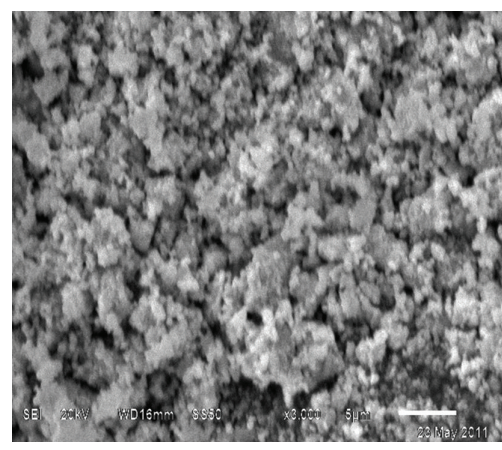

(a)

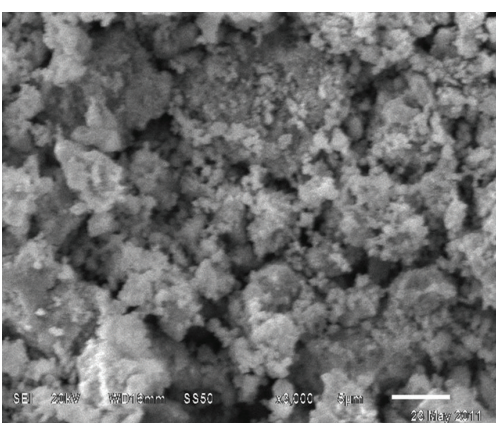

(d)

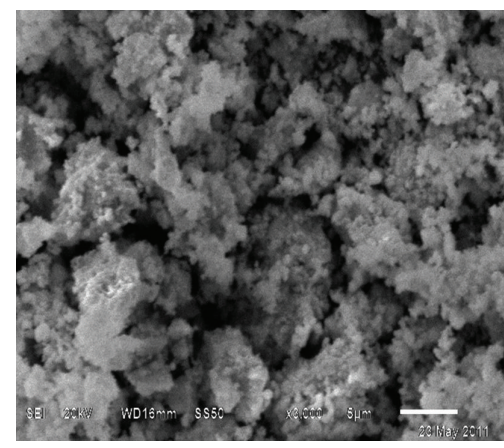

(b)

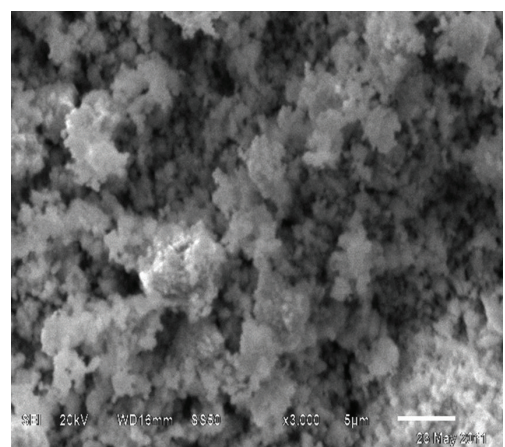

(e)

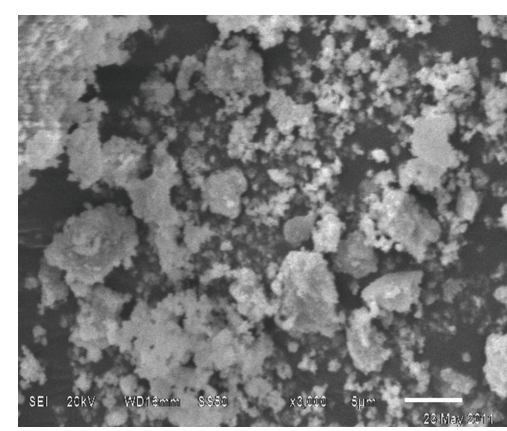

(c)

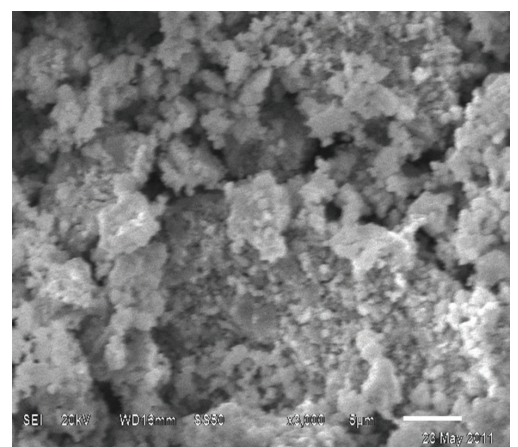

(f)

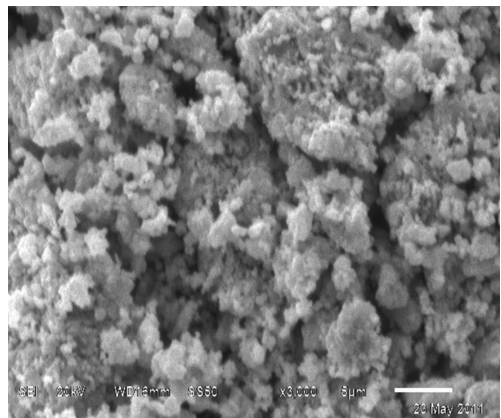

(g)

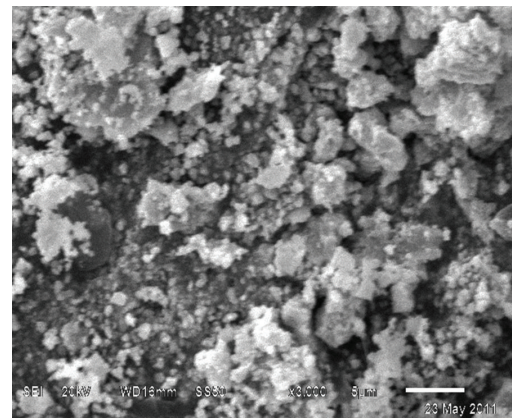

(h)

FIGURE 5: SEM images of $\mathrm{Ni}_{0.65-x} \mathrm{Zn}_{0.35} \mathrm{Co}_{x} \mathrm{Fe}_{2} \mathrm{O}_{4}(x=0.0,0.04,0.08,0.12,0.16,0.20,0.24,0.28)$. 


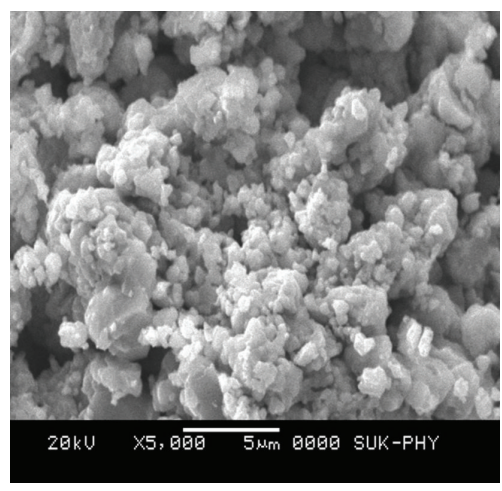

(a)

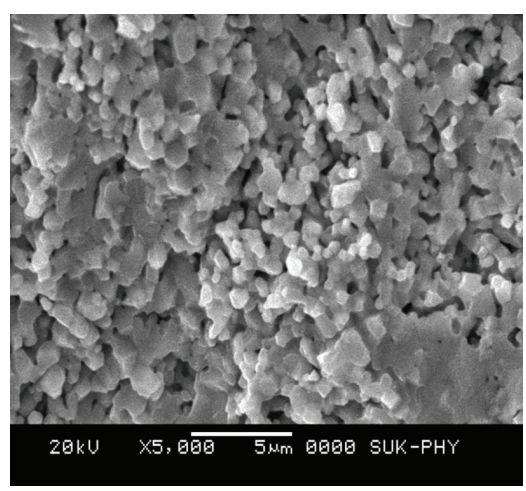

(b)

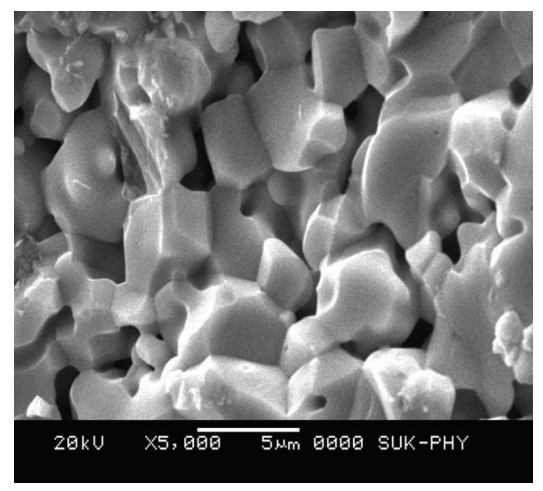

(c)

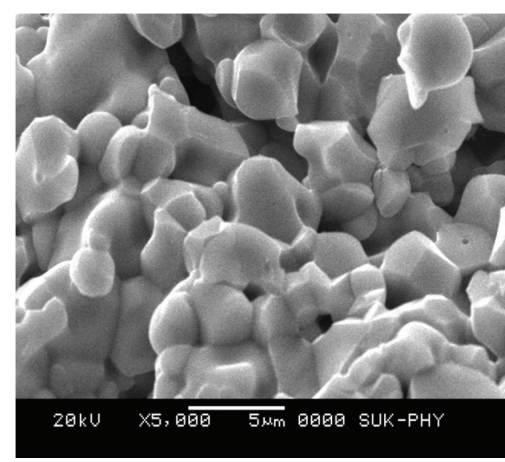

(d)

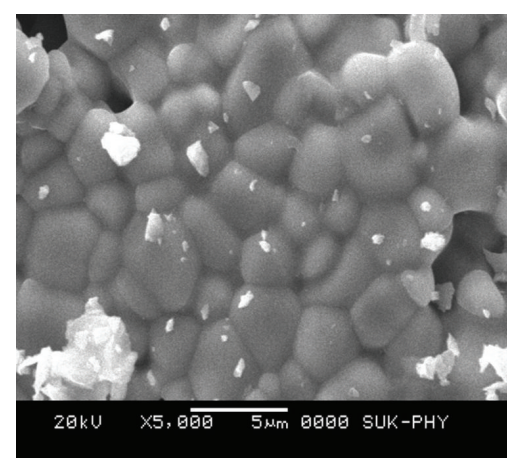

(e)

FIgure 6: SEM images of $\mathrm{Ni}_{0.65-x} \mathrm{Zn}_{0.35} \mathrm{Cu}_{x} \mathrm{Fe}_{2} \mathrm{O}_{4}(x=0.06,0.12,0.18,0.24,0.30)$.

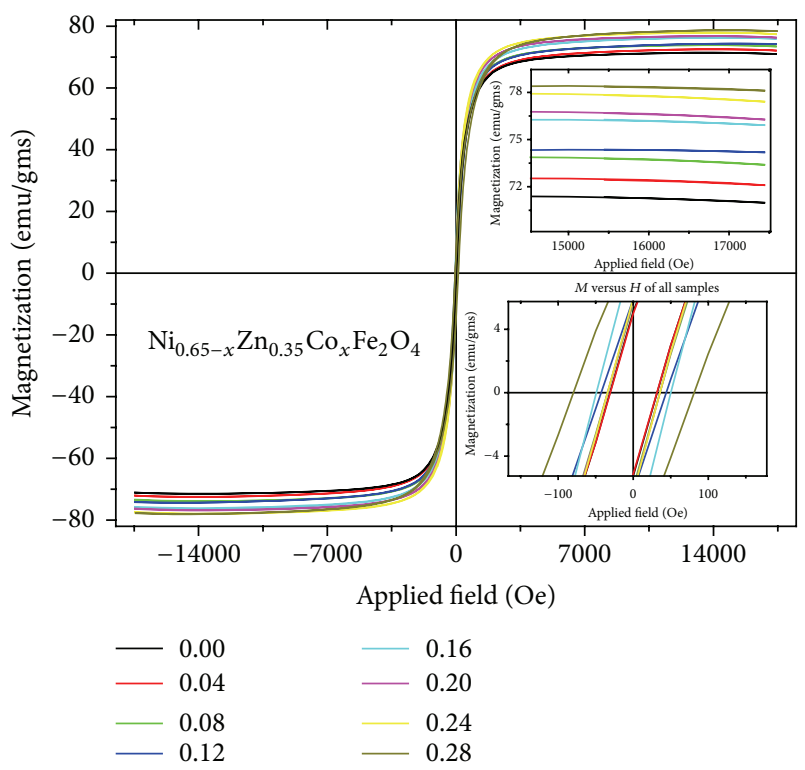

Figure 7: Hysteresis curves of cobalt substituted samples.

the interaction between the various magnetic ions located at $\mathrm{B}$-site (BB interaction), and the interaction of magnetic ions at $\mathrm{A}$-site with those at $\mathrm{B}$-site ( $\mathrm{AB}$ interaction); of these, $\mathrm{AB}$ interaction predominates in strength over $\mathrm{AA}$ and $\mathrm{BB}$ interactions. The net magnetic moment of the lattice is the difference between the magnetic moments of $\mathrm{B}$ and $\mathrm{A}$

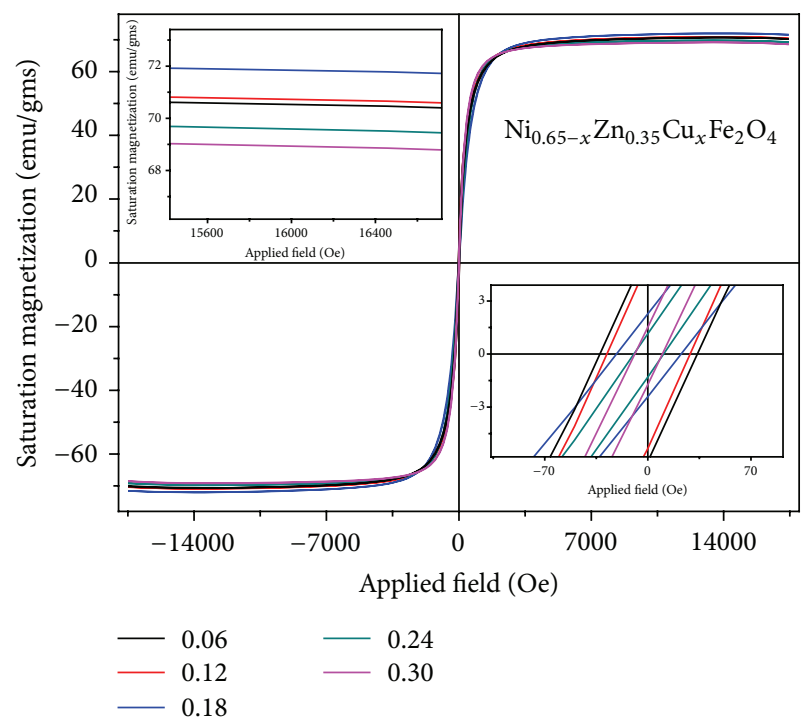

Figure 8: Hysteresis curves of copper substituted samples.

sublattices, that is, $M_{\mathrm{B}}-M_{\mathrm{A}}$. As these exchange interactions are greatly influenced by the nature of the ions present at both A- and B-sublattices, it is necessary to understand the distribution of cations over both the sublattices.

It is well known that $\mathrm{Zn}^{2+}$ ions have strong preference for A-sites, whereas $\mathrm{Ni}^{2+}, \mathrm{Co}^{2+}$, and $\mathrm{Cu}^{2+}$ ions have their tendency towards B-sites [12], while $\mathrm{Fe}^{3+}$ ions occupy both 


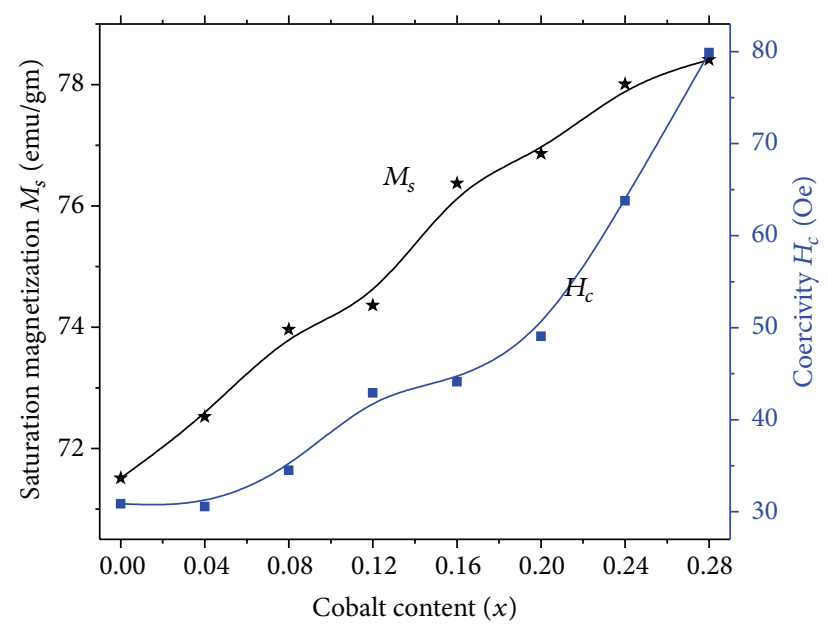

FIGURE 9: Variations in saturation magnetization and coercivity as a function of cobalt concentration.

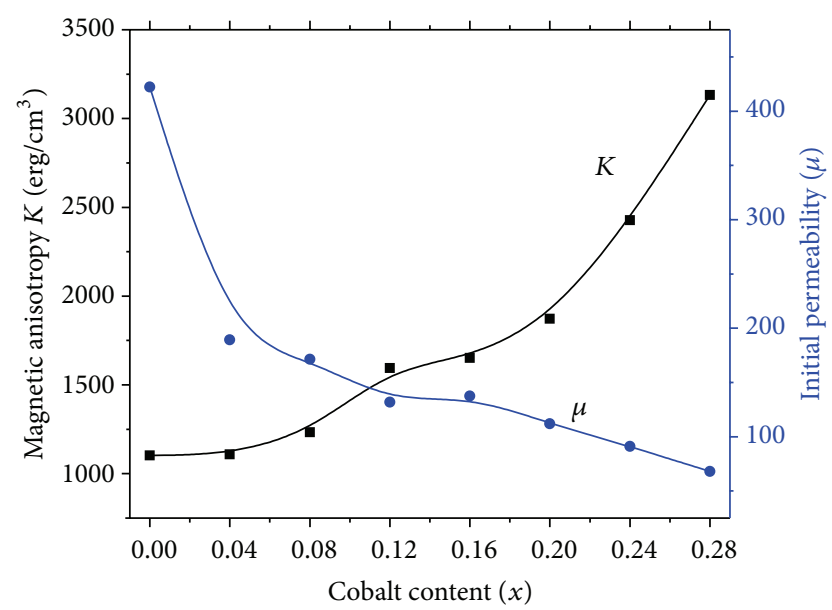

FIGURE 10: Variations in magnetic anisotropy and initial permeability as a function of cobalt concentration.

A- and B-sites. Cobalt ions $\left(3 \mu_{\mathrm{B}}\right)$ tend to replace nickel ions $\left(2 \mu_{\mathrm{B}}\right)$ at $\mathrm{B}$-site producing an increase in saturation magnetization.

The presence of cobalt at B-site, in general, produces a large positive magnetic anisotropy due to trigonal distortion of the lattice. As cobalt ions tend to induce magnetic anisotropy $(K)$, it has been estimated from the following formula by considering the values of saturation magnetization and coercivity noticed from the hysteresis loops:

$$
H_{C}=\frac{2 K}{M_{S}} .
$$

The magnetic anisotropy $(K)$ increases by threefold from $1102.7 \mathrm{erg} / \mathrm{cm}^{3}$ to $3131.7 \mathrm{erg} \cdot \mathrm{cm}^{3}$ with increasing cobalt concentration. This increase in magnetic anisotropy also tends to increase the coercivity with increasing cobalt concentration.

The interaction between ferromagnetic Fe, Ni ions at BSite and Fe ions at A-site is very strong compared to that of paramagnetic $\mathrm{Cu}$ ions at $\mathrm{B}$-site and ferromagnetic $\mathrm{Fe}$ ions at A-site. Since the magnetic moment of copper ions is less than that of $\mathrm{Ni}$ ions, occupancy of $\mathrm{Cu}$ ions at B-sites leads to a decrease in net magnetic moment; if $\mathrm{Cu}$ ions occupy A-sites pushing $\mathrm{Zn}$ ions to $\mathrm{B}$-sites, net magnetic moment will increase. Copper ions $\left(1 \mu_{\mathrm{B}}\right)$ replacing nickel ions $\left(2 \mu_{\mathrm{B}}\right)$ at B-site should decrease their magnetization due to their diamagnetic nature, but a small initial increase followed by a decrease infers the possible entry of small amount of copper ions to A-sites initially by pushing few $\mathrm{Fe}^{3+}$ ions into Bsites [13]. Similar behavior in saturation magnetization in copper containing ferrites is reported [14]. The observed variations in saturation magnetization, coercivity, and magnetic anisotropy as a function of copper concentration are shown in Figures 11 and 12.

Compositional dependence of initial permeability of $\mathrm{Ni}_{0.65-x} \mathrm{M}_{x} \mathrm{Zn}_{0.35} \mathrm{Fe}_{2} \mathrm{O}_{4}(\mathrm{M}=\mathrm{Co}, \mathrm{Cu})$ is shown in Figures 10 and 12. A steady decrease in initial permeability has been noticed with increasing cobalt content which might be attributed to increase in magnetic anisotropy with cobalt concentration, restricting both the domain wall motion and domain rotation as suggested by Globus [15].

Consider the following:

$$
\mu_{i} \propto \frac{M_{s}^{2} D}{K},
$$

where $D$ is the particle diameter, $K$ is magnetic anisotropy, and $M_{s}$ is saturation magnetization.

On the basis of the above equation, in case of copper ferrites, variation in anisotropy with copper content could not be taken as a vital parameter affecting the initial permeability. Copper being a sintering aid, it usually promotes the grain growth, and hence, more flux linkage through the ferrite grains increases the initial permeability. The observed decrease in initial permeability for samples up to $x=0.12$ has been attributed to increased intragranular porosity resulting from discontinuous grain growth, and the same has been reported by Burke [16]. For the compositions $x=0.18$ and 0.24 , the porosity reduces drastically which in turn produces high initial permeability, and introducing copper into the $\mathrm{Ni}-\mathrm{Zn}$ ferrite could raise the spin rotational contribution supporting this contention [13]. The variations in porosity and initial permeability as a function of copper content are shown in Figure 13.

\section{Conclusion}

Single phase spinel structure for sol-gel synthesized $\mathrm{Ni}_{0.65-x} \mathrm{M}_{x} \mathrm{Zn}_{0.35} \mathrm{Fe}_{2} \mathrm{O}_{4} \quad(\mathrm{M}=\mathrm{Co}, \mathrm{Cu})$ is confirmed through X-ray diffraction studies. Variations in saturation magnetization and initial permeability are understood in terms of magnetic anisotropy for cobalt and sintering aid behavior of copper. The abrupt increase in permeability with copper is attributed to variation in porosity. The observed variations in magnetic anisotropy and initial permeability with both cobalt and copper suggest that $\mathrm{Ni}-\mathrm{Zn}$ ferrite doped with both cobalt and copper might be suitable at higher frequencies. 


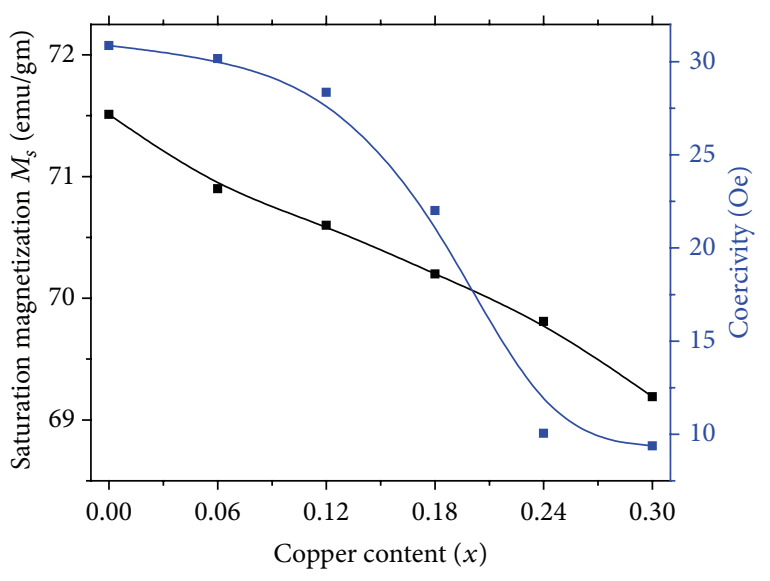

FIGURE 11: Variations in saturation magnetization and coercivity versus copper concentration.

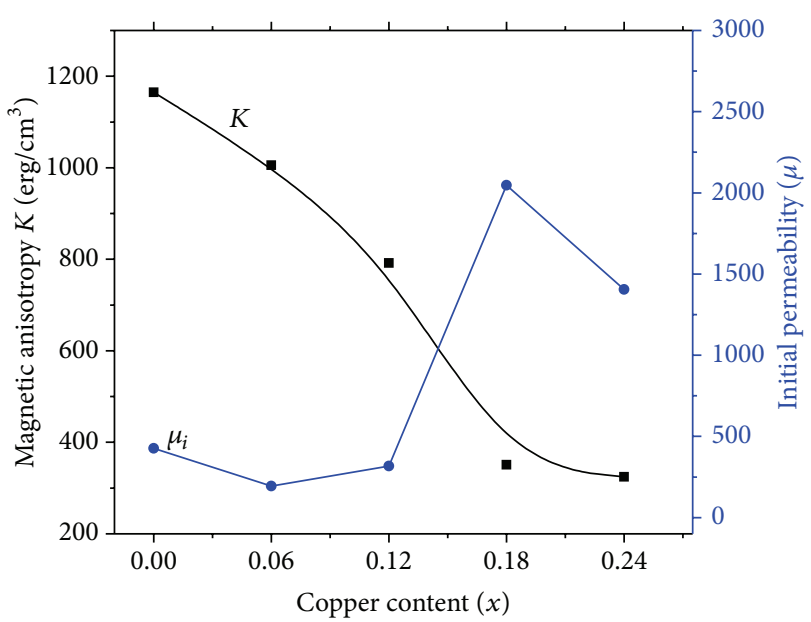

FIGURE 12: Variations in magnetic anisotropy and initial permeability versus copper concentration.

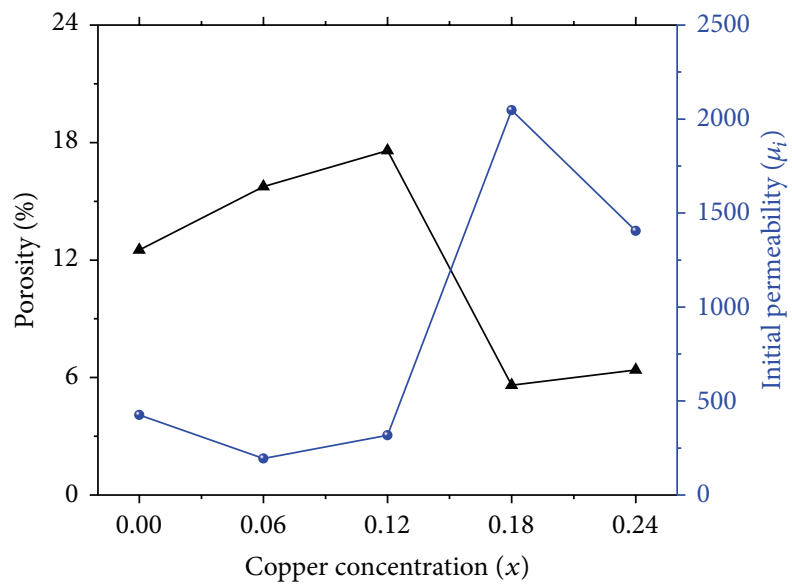

FIGURE 13: Variations in porosity and initial permeability versus copper concentration.

\section{Acknowledgments}

The part of this work (X-ray diffraction) was performed at UGC-DAE Consortium for Scientific Research, Indore. Authors also thank Mr. Shiva Kumar, IIT Kanpur, for VSM measurements. One of the authors (GSVRK Choudary) is thankful to the management of Bhavan's Vivekananda College, Sainikpuri, Secunderabad, for their constant support. The authors also thank Department of Science and Technology (DST) and SAIF, IIT Mumbai, India, for providing their scanning electron microscope.

\section{References}

[1] I. H. Gul, W. Ahmed, and A. Maqsood, "Electrical and magnetic characterization of nanocrystalline $\mathrm{Ni}-\mathrm{Zn}$ ferrite synthesis by co-precipitation route," Journal of Magnetism and Magnetic Materials, vol. 320, no. 3-4, pp. 270-275, 2008.

[2] M. Popovici, C. Savii, D. Niznansky et al., "Nanocrystalline NiZn ferrites prepared by sol-gel method," Journal of Optoelectronics and Advanced Materials, vol. 5, no. 1, pp. 251-256, 2003.

[3] A. M. Kumar, K. H. Rao, and J. M. Greneche, "Mössbauer investigation on Ni-Zn nanoferrite with the highest saturation magnetization," Journal of Applied Physics, vol. 105, no. 7, Article ID 073919, 5 pages, 2009.

[4] A. M. Kumar, M. C. Varma, C. L. Dube, K. H. Rao, and S. C. Kashyap, "Development of Ni-Zn nanoferrite core material with improved saturation magnetization and DC resistivity," Journal of Magnetism and Magnetic Materials, vol. 320, no. 14, pp. 19952000, 2008.

[5] K. Kondo, T. Chiba, and S. Yamada, "Effect of microstructure on magnetic properties of Ni-Zn ferrites," Journal of Magnetism and Magnetic Materials, vol. 254-255, pp. 541-543, 2003.

[6] J. B. Nelson and D. P. Riley, "An experimental investigation of extrapolation methods in the derivation of accurate unit-cell dimensions of crystals," Proceedings of the Physical Society, vol. 57, no. 3, pp. 160-176, 1945.

[7] N. Rezlescu, E. Rezlescu, C.-L. Sava, F. Tudorache, and P. D. Popa, "Effects of some ionic substitutions on sintering, structure and humidity sensitivity of $\mathrm{MgCu}$ ferrite," Physica Status Solidi A, vol. 201, no. 1, pp. 17-25, 2004.

[8] S. T. Hugh, C. ONeill, and A. Navrotsky, "Simple spinels: crystallographic parameters, cation radii, lattice energies and cation distribution," American Mineralogist, vol. 68, pp. 181-194, 1983.

[9] R. D. Shannon and C. T. Prewitt, "Structural crystallography and crystal chemistry," Acta Crystallographica B, vol. 25, pp. 925-946, 1969.

[10] R. D. Shannon, "Crystal physics, diffraction, theoretical and general crystallography," Acta Crystallographica A, vol. 32, pp. 751-767, 1976.

[11] L. Neel, “Théorie du traînage magnétique des ferromagnétiques en grains fins avec applications aux terres cuites," Annals of Geophysics, vol. 5, pp. 99-136, 1949.

[12] S. Ghosh, P. Ayyub, N. Kumar, S. A. Khan, and D. Banerjee, "In situ monitoring of electrical resistance of nanoferrite thin film irradiated by $190 \mathrm{MeV} \mathrm{Au}^{14+}$ ions," Nuclear Instruments and Methods in Physics Research B, vol. 77, pp. 510-515, 2003.

[13] A. Ghasemi, A. Ashrafizadeh, A. Paesano et al., "The role of copper ions on the structural and magnetic characteristics of MgZn 
ferrite nanoparticles and thin films," Journal of Magnetism and Magnetic Materials, vol. 322, no. 20, pp. 3064-3071, 2010.

[14] J. Slama, A. Gruskova, M. Usakova, E. Usak, and R. Dosoudil, "Contribution to analysis of Cu-substituted NiZn ferrites," Journal of Magnetism and Magnetic Materials, vol. 321, no. 19, pp. 3346-3351, 2009.

[15] A. Globus, Journal of Physics, vol. C38-1, p. C1-1, 1977.

[16] J. E. Burke, "Role of grain boundaries in sintering," Journal of the American Ceramic Society, vol. 40, no. 3, pp. 80-85, 1957. 

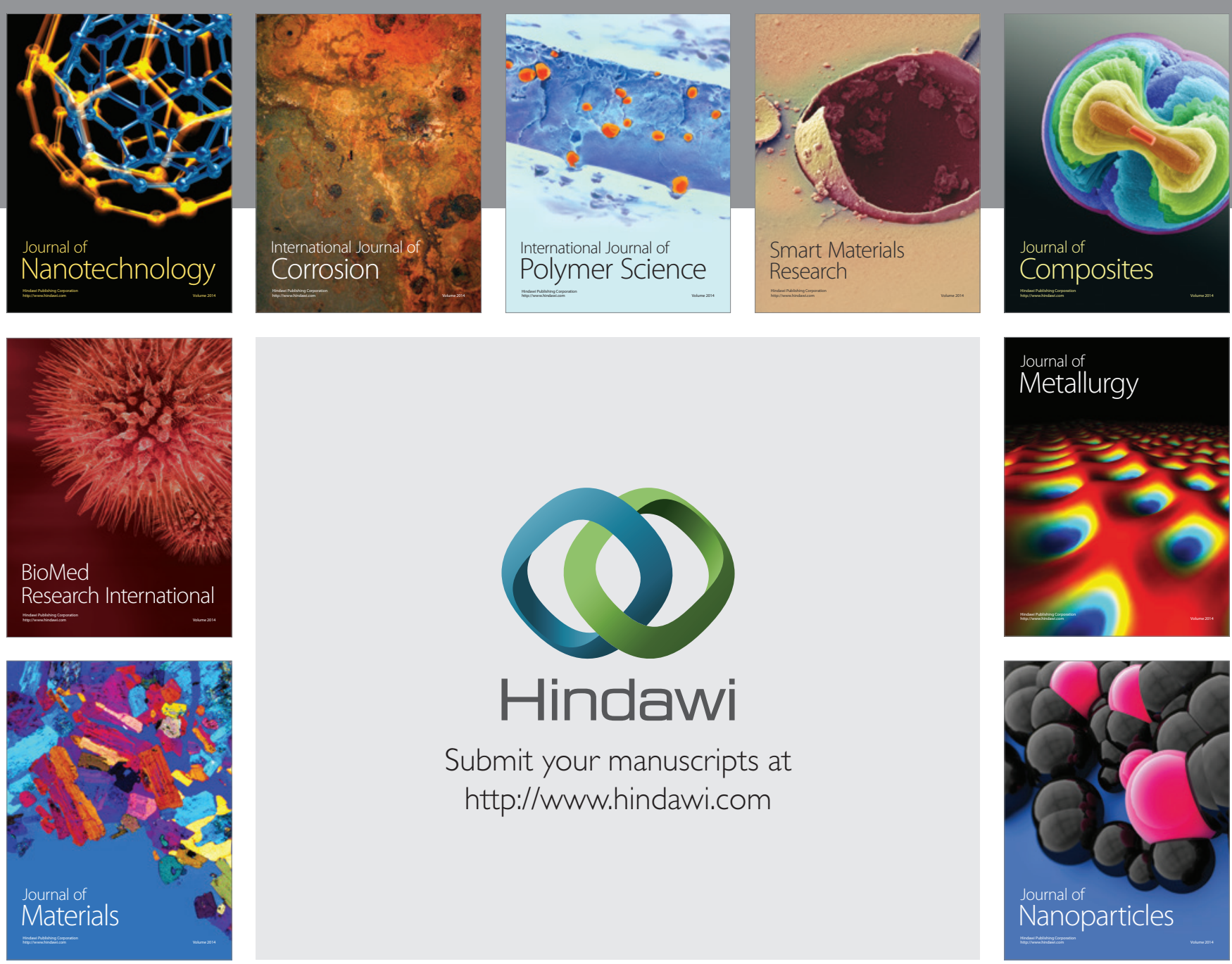

Submit your manuscripts at http://www.hindawi.com
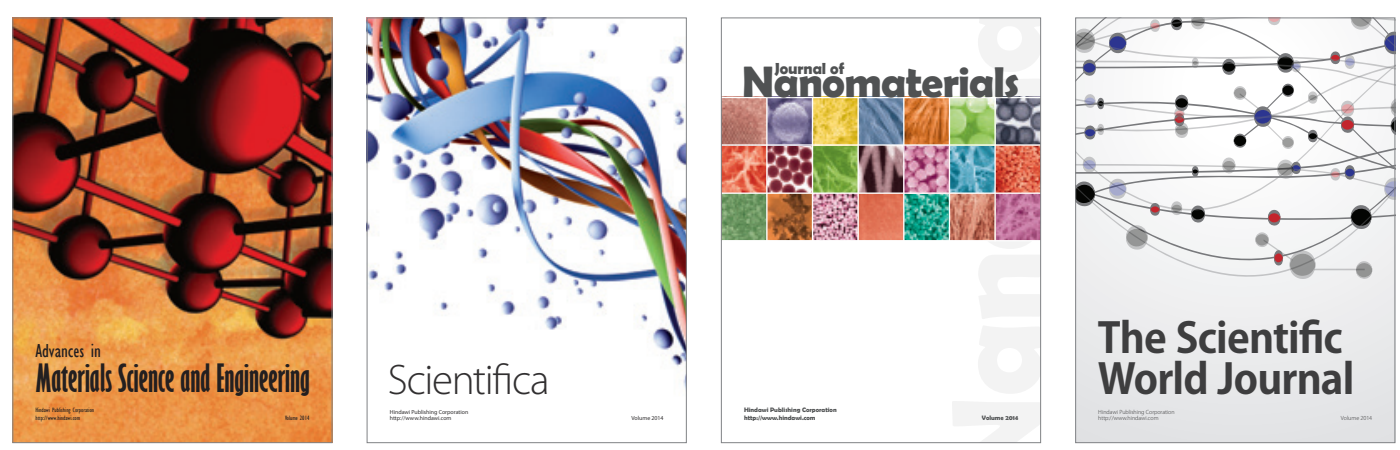

\section{The Scientific World Journal}
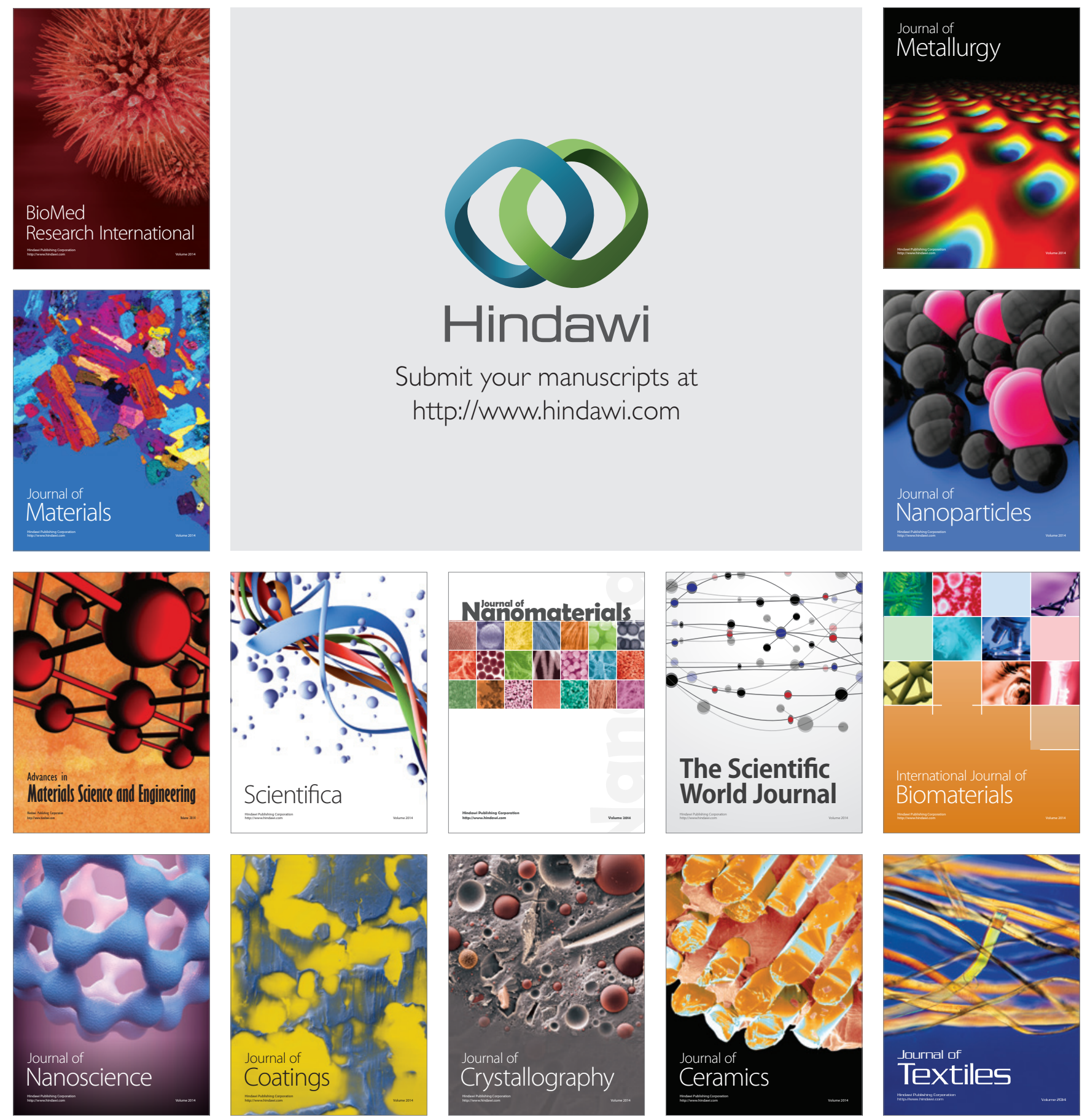